Article

\title{
Winery Wastewater Treatment by Microalgae to Produce Low-Cost Biomass for Energy Production Purposes
}

\author{
Elena Spennati, Alessandro Alberto Casazza *(i) and Attilio Converti $(\mathbb{D}$ \\ Department of Civil, Chemical and Environmental Engineering, University of Genoa, I-16145 Genoa, Italy; \\ elena.spennati@edu.unige.it (E.S.); converti@unige.it (A.C.) \\ * Correspondence: alessandro.casazza@unige.it; Tel.: +39-010-3352584
}

Received: 15 April 2020; Accepted: 11 May 2020; Published: 15 May 2020

check for updates

\begin{abstract}
Even though biofuel production from microalgae has become more and more attractive in recent years, it is limited especially by the high cost of microalgae cultivation. However, microalgae can be grown in wastewater in order to reduce their production cost and, at the same time, the polluting impact of wastewaters. Winery wastewaters, which are abundantly released from the wine making process, have a large pollution impact related to their high loads of total solids, chemical oxygen demand (COD) and polyphenol concentration. In this research work a co-culture of Chlorella vulgaris and Arthrospira platensis was used to treat three different winery wastewaters from different steps of the wine production process, in order to produce low-cost biomass intended for biofuel production. Growth of the co-culture and reduction of wastewater pollutant impact were followed by daily determinations of biomass concentration, COD and polyphenol content. The highest productivities of biomass (0.66 $\mathrm{g}_{\text {Dry Weight }} / \mathrm{L} \cdot$ day) and lipids $\left(7.10 \pm 0.22 \mathrm{~g}_{\mathrm{Lipid}} / 100 \mathrm{~L} \cdot\right.$ day $)$ were obtained using $20 \%$ of second washing winery wastewater after 4 days of treatment. Moreover, COD and polyphenol content of the three different wastewaters were reduced by the co-culture by more than $92 \%$ and $50 \%$, respectively. These results suggest that winery wastewaters can be used successfully for the growth of $A$. platensis and C. vulgaris co-culture in order to obtain inexpensive biomass for energy production purposes.
\end{abstract}

Keywords: microalgae co-culture; COD removal; polyphenol removal; winery wastewater valorization; biomass production

\section{Introduction}

The reduction of fossil fuels reserves and the continuously increasing demand for energy around the world has led to the necessity to find an eco-sustainable alternative to conventional fuels. In the last few years, biofuel production from different plant sources has been increasingly studied by researchers [1]. The production of third-generation biofuels from raw materials that do not compete with food crops is in fact attracting more and more attention. Third-generation biofuels can be produced from microalgal biomasses or from their intracellular components such as lipids. Moreover, their production, if compared to conventional biomasses, reduces land and water utilization along with the use of pesticides [2].

Microalgae are unicellular microorganisms able to grow under autotrophic, heterotrophic or mixotrophic conditions depending on the carbon source used in their metabolism as well as light conditions [3]. They are composed mainly of lipids, proteins and carbohydrates, whose relative proportions depend in particular on the species and growth conditions [4]. They are generally used for human or animal nutrition [5], or extraction of added-values components for chemical and pharmaceutical industries [6], but also for biofuel production [7]. 
The main limit of the production of biofuels from microalgae is due to the high cost of biomass cultivation, making them not cost-competitive, on a large scale, when compared with conventional biofuels produced from agricultural waste or conventional biomasses. The only possibility to make the microalgae biofuels more competitive on the global market is to apply the biorefinery concept. Thanks to their capability of also metabolizing organic carbon, microalgae can in fact be grown in wastewaters, thus reducing the use of fresh water, the cost of growth medium, the energy consumption and, at the same time, the wastewater polluting impact [8]. There are several studies in the literature focusing on the use of microalgae to treat wastewaters such as municipal wastewater [9] and textile wastewater [10], among others.

Winery wastewaters (WWWs) are released from different activities of the wine making process, namely tank washing, transfer, bottling and filtration [11]. The polluting impact of WWWs is related to their high organic load (polyphenolic compounds, sugars, organic acids and esters), low $\mathrm{pH}(3-5)$, content of suspended particles and large volumes (0.5-14 L per liter of wine produced) [12]. Among them, polyphenols are considered hazardous compounds because they are not mineralized by conventional biological treatments [13]. Owing to the release of organic compounds and inorganic ions, their disposal in land without adequate treatment can change the physicochemical properties of groundwater such as color, $\mathrm{pH}$ and electrical conductivity, among others [14]. WWWs can be treated by biological or physicochemical processes, membrane filtration and separation, advanced oxidation or combined biological and advanced chemical processes [12]. Among these, biological processes are the most appropriate to treat WWWs because of their high organic load.

The aim of this work is to grow a co-culture of Arthrospira platensis and Chlorella vulgaris, the most common microalgae belonging to the prokaryotic and eukaryotic phyla, respectively, using WWWs as culture media in order to reduce, on one hand, the production cost of biomass to be used for energy production purposes and, on the other, the wastewater pollution load. Particularly, three different WWWs, namely the first and second tank washing waters and that from the filtration equipment, were investigated after dilution at different concentrations in Bold's Basal Medium. The reduction of the wastewater pollution load was evaluated in terms of reduction of polyphenol concentration and chemical oxygen demand.

\section{Materials and Methods}

\subsection{Microalgae Strains and Culture Conditions}

To produce the inoculum, the co-culture of Chlorella vulgaris CCAP 211 (Culture Collection of Algae and Protozoa, Argyll, UK) and Arthrospira platensis UTEX 1926 (University of Texas Culture Collection, TX, USA) was cultivated in Erlenmeyer flasks (1000 mL) using Bold Basal Medium (BBM) with a continuous air supply at room temperature $\left(25^{\circ} \mathrm{C}\right)$. All the chemicals were purchased from Sigma-Aldrich (St. Louis, MO, USA). The three second fermentation winery wastewaters (WWWs), namely those from the first (W1) and second (W2) tank washings as well as that from the filtration equipment (W3), were provided by a winery cellar located in the Piemonte region, Italy.

\subsection{Experimental Design}

After inoculation $\left(0.5 \mathrm{~g}_{\mathrm{DW}} / \mathrm{L}\right)$, the co-culture was grown in $200-\mathrm{mL}$ bubblers using the three WWWs diluted with BBM up to $10 \%, 20 \%, 50 \%$ and $100 \%(\mathrm{v} / \mathrm{v})$ under continuous air supply and illumination ( $82 \pm 5 \mu \mathrm{mol}$ photons $/ \mathrm{m}^{2} \mathrm{~s}$ ) for 15 days. WWWs were used without preliminary treatments. Two different sets of control runs were performed, where the co-culture was grown under the same conditions using only BBM (C). Moreover, the three wastewaters were exposed to air bubbling and light without microalgal inoculum, in order to check the possible effect of autochthonous microorganisms on pollutant removal (C1W, $\mathrm{C} 2 \mathrm{~W}$ and $\mathrm{C} 3 \mathrm{~W}$ for $1 \mathrm{~W}, 2 \mathrm{~W}$ and $3 \mathrm{~W}$, respectively).

Total microalgae concentration was determined daily by dry weight, taking into account the total suspended solid (TSS) content of WWWs expressed in g/L. Aliquots of the medium were collected 
and filtered daily to evaluate the reduction in the concentrations of the pollutants. At the end of the growth period, the microalgal biomass was centrifuged at 6036 $\times g$ for 15 min (MF20-R, Alliance Bio Expertise, Guipry, France) and freeze dried (Alpha 1-2 LD plus, Martin Christ Gefriertrocknungsanlagen, Osterode am Harz, Germany). Supernatant, microalgal biomass and filtrate were collected and frozen at $-20^{\circ} \mathrm{C}$ for subsequent analyses.

Runs were carried out in duplicate, while biomass concentration and WWW analyses were done in triplicate. Results were expressed as mean values \pm standard deviations.

\subsection{Biomass and Winery Wastewaters Characterization}

WWWs were characterized in terms of contents of total solids (TS), total suspended solids (TSS) and volatile solids (VS) according to the standard methods of APHA (APHA, 1999).

Chemical oxygen demand (COD) was determined by colorimetric analysis. Briefly, $1.5 \mathrm{~mL}$ of sample and $2.5 \mathrm{~mL}$ of $\mathrm{HgSO}_{4}-\mathrm{H}_{2} \mathrm{SO}_{4}: \mathrm{K}_{2} \mathrm{Cr}_{2} \mathrm{O}_{7}(1: 4 \mathrm{v} / \mathrm{v})$ solution were added to $10-\mathrm{mL}$ glass tubes. The tubes were then heated at $150^{\circ} \mathrm{C}$ for $2 \mathrm{~h}$, and the absorbance was measured at $620 \mathrm{~nm}\left(\mathrm{ABS}_{620}\right)$ with a UV-Vis spectrophotometer (Photometer PF-12 ${ }^{\text {plus }}$, Macherey-Nagel, Düren, Germany). A calibration curve was made with standard solutions of potassium hydrogen phthalate, and the unknown COD $\left(X_{1}\right)$ estimated by the equation $\left(R^{2}=0.9999\right)$ :

$$
\mathrm{ABS}_{620}=0.0004 X_{1}-0.0011
$$

and expressed in grams of oxygen per liter $\left(\mathrm{g}_{\mathrm{O} 2} / \mathrm{L}\right)$. Polyphenolic compounds (PC) were quantified by the Folin-Ciocalteu assay [15] and expressed as milligrams of gallic acid equivalents per milliliter of solvent $\left(\mathrm{mg}_{\mathrm{GAE}} / \mathrm{mL}\right)$. A calibration curve was prepared with standard solutions of gallic acid, and the unknown total polyphenol concentration $\left(X_{2}\right)$ estimated by the equation $\left(R^{2}=0.9988\right)$ :

$$
\mathrm{ABS}_{725}=0.0018 \mathrm{X}_{2}
$$

both COD and total polyphenol content of the WWWs were quantified daily, in order to evaluate the degradation efficiency of the microalgal co-culture.

The lipid fraction was extracted with a 2:1 (v/v) chloroform/methanol solution as solvent, following a modified version of the Folch method [16].

The co-culture elemental composition, in terms of carbon, hydrogen, nitrogen and sulfur contents, was determined with a CHNS-O elemental analyzer (FLASH EA1112, ThermoQuest, Cleveland, OH, USA) following the methodology described by [17] and expressed as percentages.

\subsection{Kinetic Parameters of Microalgae Growth}

The specific grow rate $(\mu)$, expressed in day $^{-1}$, was calculated by the equation:

$$
\mu=\frac{1}{t} \ln \left(\frac{X_{\mathrm{f}}}{X_{0}}\right)
$$

where $t$ is the overall cultivation time (days), while $X_{0}$ and $X_{\mathrm{f}}$ are the starting and final biomass concentrations $\left(\mathrm{g}_{\mathrm{DW}} / \mathrm{L}\right)$, respectively.

The value of $\mu$ at maximum biomass concentration $\left(\mu_{\max }\right)$, expressed in day $^{-1}$, was calculated by the equation:

$$
\mu_{\max }=\frac{1}{t_{\max }} \ln \left(\frac{X_{\max }}{X_{0}}\right)
$$

where $X_{\max }$ is the maximum biomass concentration $\left(\mathrm{g}_{\mathrm{DW}} / \mathrm{L}\right)$ and $t_{\max }$ the time needed to reach it. 
Biomass productivity at the end of cultivation $(v)$ and its value at $X_{\max }\left(v_{\max }\right)$, both expressed in $\mathrm{g}_{\mathrm{DW}} / \mathrm{L} \cdot$ day, were calculated as follows:

$$
\begin{gathered}
v=\frac{X_{\mathrm{f}}}{t} \\
v_{\max }=\frac{X_{\max }}{t}
\end{gathered}
$$

Defining the lipid content of biomass $\left(C_{\mathrm{L}}, \mathrm{g}_{\mathrm{L}} / 100 \mathrm{~g}_{\mathrm{DW}}\right)$ as the fraction of lipid mass referred to $100 \mathrm{~g}$ of dry biomass, the lipid productivity $\left(v_{\mathrm{L}}\right)$, expressed in $\mathrm{g}_{\mathrm{L}} / 100 \cdot \mathrm{L} \cdot$ day, was calculated as:

$$
v_{\mathrm{L}}=\frac{C_{\mathrm{L}}\left(X_{\mathrm{f}}-X_{0}\right)}{t}
$$

\section{Results and Discussions}

\subsection{Winery Wastewater Characterization}

Three different winery wastewaters (WWWs), from three different steps of the wine making process, namely first (W1) and second (W2) tank washings, and filtration (W3), were used as media to grow the Arthrospira platensis and Chlorella vulgaris co-culture. Wastewaters were characterized in terms of contents of total solids (TS), total suspended solids (TSS) and polyphenol compounds (PC) as

\begin{tabular}{|c|c|c|c|c|c|}
\hline & $\begin{array}{l}T_{S}^{a} \\
(g / L)\end{array}$ & $\begin{array}{c}\text { TSS }^{b} \\
(g / L)\end{array}$ & $\mathrm{pH}$ & $\begin{array}{l}\mathrm{COD}^{\mathrm{c}} \\
\left(\mathrm{gO}_{2} / \mathrm{L}\right)\end{array}$ & $\begin{array}{c}\mathrm{PC}^{\mathrm{d}} \\
\left(\mathrm{mg}_{\mathrm{GAE}} / \mathrm{L}\right)\end{array}$ \\
\hline $\mathrm{W} 1^{\mathrm{e}}$ & $13.15 \pm 0.48$ & $1.26 \pm 0.02$ & 3.42 & $116.30 \pm 8.13$ & $143.33 \pm 0.13$ \\
\hline$W 2^{f}$ & $11.51 \pm 0.24$ & $0.39 \pm 0.04$ & 3.31 & $119.30 \pm 1.06$ & $139.72 \pm 0.03$ \\
\hline W3 ${ }^{g}$ & $4.69 \pm 0.24$ & $0.60 \pm 0.05$ & 3.82 & $36.90 \pm 0.88$ & $98.52 \pm 0.23$ \\
\hline
\end{tabular}
well as $\mathrm{pH}$ and chemical oxygen demand (COD), whose results are listed in Table 1.

Table 1. Winery wastewaters characterization.

a total solids, ${ }^{b}$ total suspended solids, ${ }^{\mathrm{c}}$ chemical oxygen demand, ${ }^{\mathrm{d}}$ polyphenol content, ${ }^{\mathrm{e}}$ first tank washing wastewater, ${ }^{\mathrm{f}}$ second tank washing wastewater, ${ }^{\mathrm{g}}$ wastewater from the filtration equipment.

The COD content was especially high in W1 $\left(116.30 \pm 8.13 \mathrm{~g}_{\mathrm{O} 2} / \mathrm{L}\right)$ and W2 $\left(119.30 \pm 1.06 \mathrm{~g}_{\mathrm{O} 2} / \mathrm{L}\right)$ mainly due to the presence of organic compounds such as sugar and ethanol, but it was remarkably lower in W3 $\left(36.90 \pm 0.88 \mathrm{~g}_{\mathrm{O} 2} / \mathrm{L}\right)$ probably due to the lower content of total dissolved compounds $(11.89,11.12$ and $4.09 \mathrm{~g} / \mathrm{L}$ in W1, W2 and W3, respectively). The lower content of dissolved compounds in $\mathrm{W} 3$ could be related to the increased water volume used in the filtration step, which leads to dilution of the dissolved solids present in W1 and W2. On the other hand, the high polyphenol concentration in the three WWWs was the likely result of the presence of soluble acidic phenolic compounds in grapes such as gallic, vanillic, syringic and protocatechuic acids [18]. In general, the qualitative characteristics of the different WWWs were comparable with the literature's data [11].

\subsection{Microalgal Biomass Growth Using Different Type and Concentration of Winery Wastewaters}

To reduce the polluting impact of WWWs and to increase the final biomass concentration, the co-culture was grown on each of them after previous dilution in Bold's Basal Medium up to 10\%, $20 \%, 50 \%$ and $100 \%(\mathrm{v} / \mathrm{v})$. Figure 1 illustrates the co-culture growth curves considering the TSS content of WWWs. No significant changes of dry weight in the controls (C1W, C2W and C3W) were observed during the 15 days, suggesting that there was no proliferation of other microorganisms. 


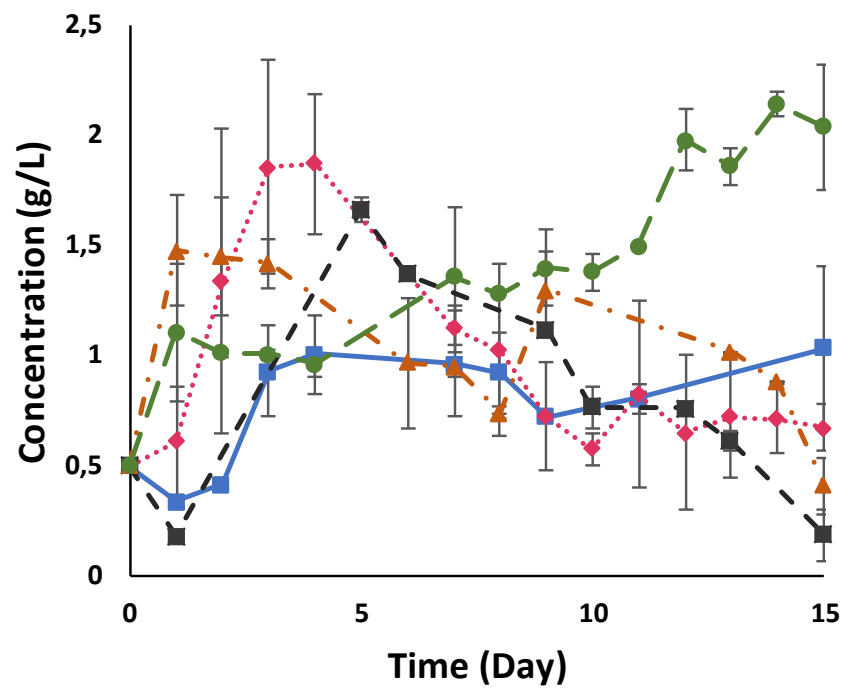

A)
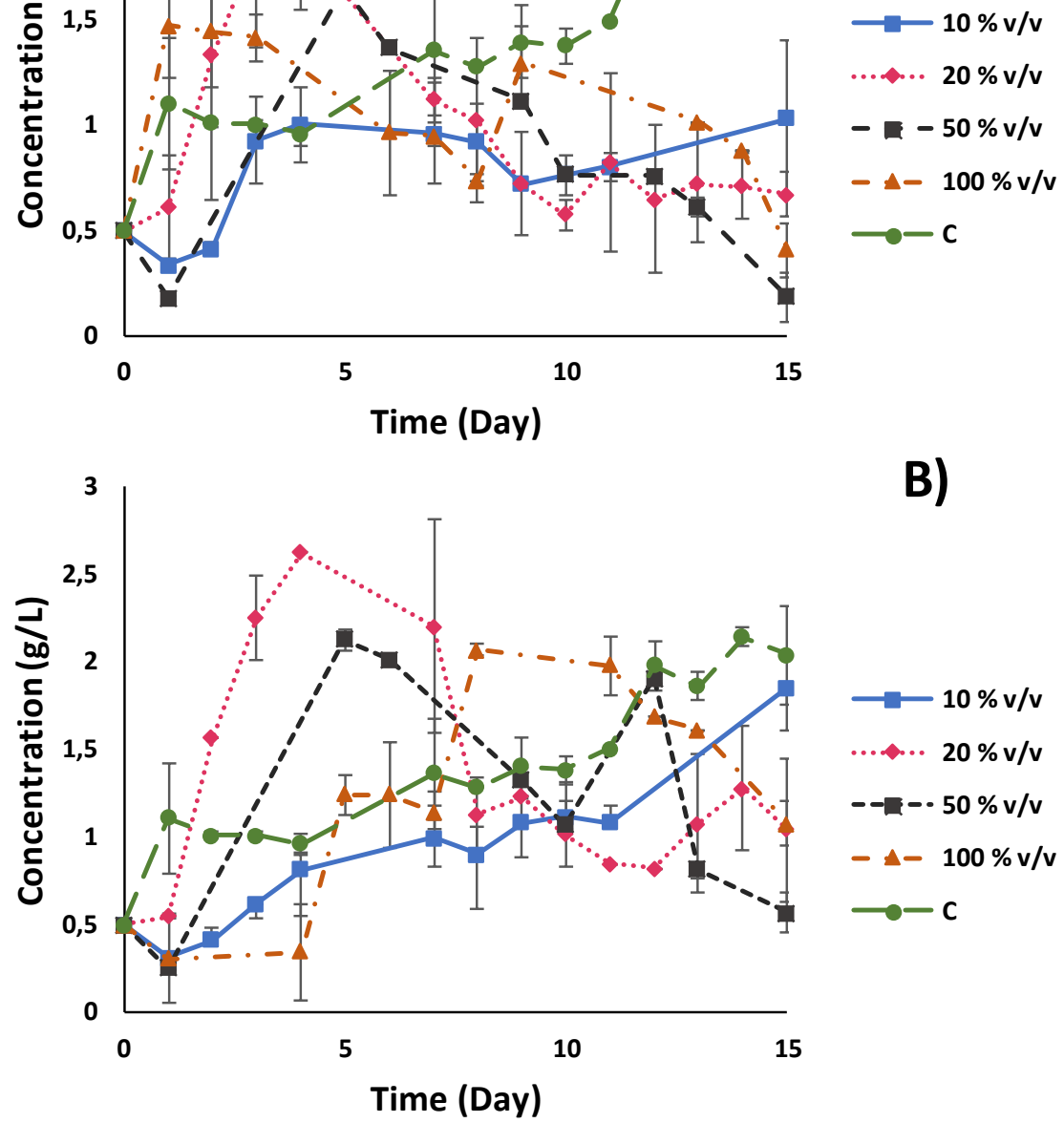

B)

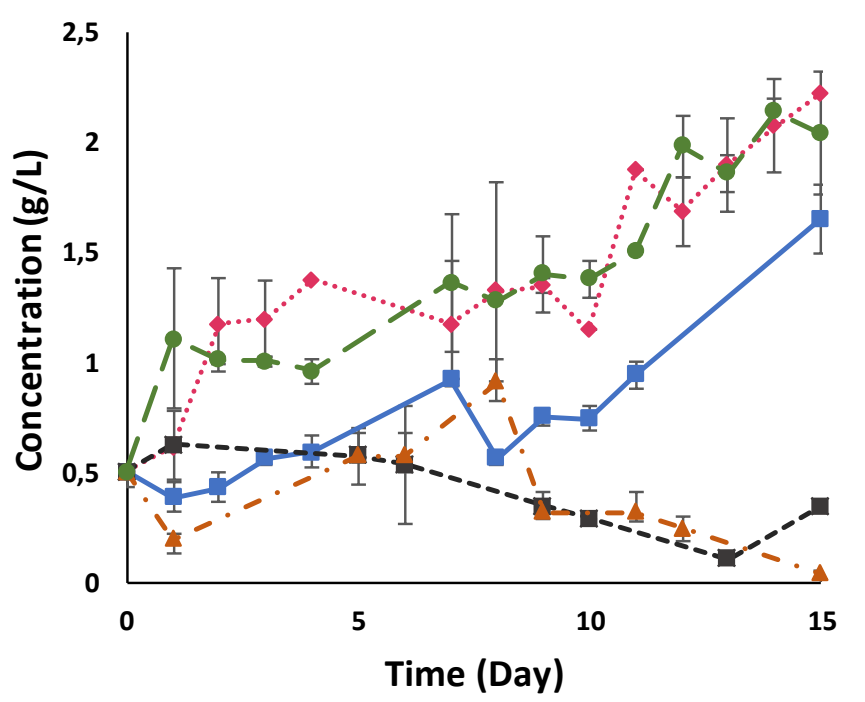

C)

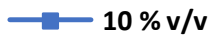

$\ldots \sim . . .20 \% \mathrm{v} / \mathrm{v}$

- - $-.50 \% \mathrm{v} / \mathrm{v}$

$-\triangle-100 \% \mathrm{v} / \mathrm{v}$

$\longrightarrow \mathrm{C}$

Figure 1. Co-culture growth curves in (A) the first tank washing wastewater (W1), (B) second tank washing wastewater (W2) and (C) wastewater from the filtration equipment (W3), after their dilution with Bold's Basal Medium up to $10 \%, 20 \%, 50 \%$ and $100 \%$ (v/v). Biomass concentration expressed as $g$ dry weight per liter. 
The co-cultures carried out in W1 quickly reached exponential growth without a clear lag phase, achieving biomass concentrations $(X)$ much higher than those obtained in the control run (Figure 1A), while a progressive $X$ decrease took place after 5 days. The only exception was the $10 \%(\mathrm{v} / \mathrm{v}) \mathrm{W} 1$ co-culture during which growth was always poorer than in the control run especially after 10 days. A maximum biomass concentration $\left(X_{\max }\right)$ of $1.87 \pm 0.32 \mathrm{~g}$ DW/L was reached in $20 \%(\mathrm{v} / \mathrm{v}) \mathrm{W} 1 \mathrm{after}$ 4 days. A qualitatively similar behavior was observed in W2 (Figure 1B), with achievement of $X_{\max }=2.63 \pm 0.00 \mathrm{~g}_{\mathrm{DW}} / \mathrm{L}$ and $2.12 \pm 0.00 \mathrm{~g} \mathrm{DW} / \mathrm{L}$ in $20 \%$ and $50 \%(\mathrm{v} / \mathrm{v})$, respectively, and subsequent decay-also in this case the co-culture behavior in $10 \%(\mathrm{v} / \mathrm{v})$ was as poor as in the control run. These results taken together suggest that the co-culture growth was inhibited by the wastewater as such, i.e., with no dilution, and limited by excess dilution (10\% v/v). Finally, in $10 \%$ and $20 \%$ (v/v) W3 (Figure 1C), the co-culture behaved similarly to the control run, reaching $X_{\max }=1.85 \pm 0.010 \mathrm{~g}_{\mathrm{DW}} / \mathrm{L}$ in the latter after as long as 14 days, while the growth was strongly inhibited at either poor $(50 \% \mathrm{v} / \mathrm{v})$ or no dilution. It is likely that filtration removed mainly readily metabolizable rather than recalcitrant carbon sources, hence especially affecting the runs carried out in more concentrated W3.

The specific grow rate $(\mu)$ of the co-culture grown only in BBM (C) calculated at the end of the growth period was higher if compared with those in the presence of $\mathrm{W} 1, \mathrm{~W} 2$ and $\mathrm{W} 3$ at the different concentrations (Table 2). Instead, the specific growth rates at maximum biomass concentration $\left(\mu_{\max }\right)$ in W1 and W2 without any dilution were higher than in the control, with the highest value of this parameter $\left(0.60 \pm 0.00 \mathrm{day}^{-1}\right)$ being obtained in the former wastewater. The same trend was observed for biomass productivity $(v)$ along with its value at $X_{\max }\left(v_{\max }\right)$ (Table 2).

Consistently with these findings, several authors reported higher biomass concentrations for microalgae cultivated under mixotrophic rather than autotrophic conditions. To provide only a few examples limited to the microorganisms used in this study, C. vulgaris concentration in the presence of $4 \mathrm{~g} / \mathrm{L}$ of glucose was $(1.40 \pm 0.10 \mathrm{~g} / \mathrm{L})$ more than 3 times higher compared with its autotrophic growth [19] and that of $A$. platensis in the presence of $0.75 \mathrm{~g} / \mathrm{L}(2.52 \mathrm{~g} / \mathrm{L}) 42.4 \%$ higher [20]. The same trend of microalgae concentration obtained in $100 \%$ (v/v) WWWs was reported by Ganeshkumar et al., who observed a reduction of Chlorella sp. concentration from $3 \times 10^{6}$ to $1.2 \times 10^{6}$ cells/mL after 10 days of growth in concentrated winery wastewater [21].

\subsection{Lipid Accumulation and Elemental Composition in Co-Culture Biomass}

The lipid content of microalgae ranges between $10 \%$ to $50 \%$ of dry weight, depending on the species and growth conditions. Their high lipid accumulation makes them a suitable source for biodiesel production by transesterification of fatty acids [22]. Moreover, the lipid content can be further increased if microalgae are grown under abiotic stress conditions in terms of light intensity, $\mathrm{pH}$ and temperature, or changing the medium composition. Particularly, microalgae cultivation in wastewater streams may increase the lipid content and help the process to become more environmentally friendly and economically advantageous [23].

In general, the co-culture cultivated in WWW had its lipid content $\left(C_{\mathrm{L}}\right)$ increased with respect to that in the control. For instance, biomass grown on $50 \%(\mathrm{v} / \mathrm{v}) \mathrm{WWWs}$ had a $C_{\mathrm{L}}$ value that was about twice the one of control biomass (Table 3), $19.66 \pm 0.00$ and $21.95 \pm 0.00 \mathrm{~g}_{\mathrm{L}} / 100 \mathrm{~g}_{\mathrm{DW}}$ for $\mathrm{W} 2$ and W3, respectively. Moreover, the lipid productivity $\left(v_{\mathrm{Lmax}}\right)$ at $X_{\max }$ obtained in the presence of WWW was higher than in the control for almost all the tests. In particular, with $20 \%$ and $50 \%$ W2 the lipid productivity reached values of $7.10 \pm 0.22$ and $6.37 \pm 0.18 \mathrm{~g}_{\mathrm{L}} / 100 \mathrm{~L} \cdot$ day, respectively.

Similar results were reported by several authors. Santana et al. [24] obtained a 50\% increase in fatty acid productivity when cultured Micractium sp. in vinasse was diluted in 50\% BBM. Kwak et al. [25] observed an increase in the lipid content of different microalgae strains grown under different stress conditions using microfluidic systems. They observed that the lipid production was highly improved in the presence of a combination of more than three stress conditions. 
Table 2. Growth and lipid production parameters of co-cultures used in the mixotrophic treatment of winery wastewaters from the first (W1) and second (W2) washing tanks and from the filtration apparatus (W3) at different concentrations in Bold's Basal Medium.

\begin{tabular}{|c|c|c|c|c|c|c|c|c|c|c|c|c|c|}
\hline Concentration & & $10 \%(v / v)$ & & & $20 \%(v / v)$ & & & $50 \%(\mathrm{v} / \mathrm{v})$ & & & $100 \%(\mathrm{v} / \mathrm{v})$ & & \\
\hline Wastewater & W1 & W2 & W3 & W1 & W2 & W3 & W1 & W2 & W3 & W1 & W2 & W3 & Control \\
\hline$X_{\mathrm{f}}{ }^{a}\left(g_{D W} / L\right)$ & $1.03 \pm 0.37$ & $1.85 \pm 0.24$ & $1.85 \pm 0.15$ & $0.67 \pm 0.10$ & $1.04 \pm 0.41$ & $2.07 \pm 0.20$ & $0.18 \pm 0.10$ & $0.84 \pm 0.00$ & $0.34 \pm 0.00$ & $0.40 \pm 0.10$ & $1.07 \pm 0.24$ & $0.03 \pm 0.01$ & $2.14 \pm 0.06$ \\
\hline$X_{\max }{ }^{b}\left(g_{D W} / L\right)$ & $1.03 \pm 0.37$ & $1.85 \pm 0.024$ & $1.85 \pm 0.10$ & $1.87 \pm 0.32$ & $2.63 \pm 0.00$ & $2.07 \pm 0.20$ & $1.66 \pm 0.05$ & $2.12 \pm 0.01$ & $0.72 \pm 0.00$ & $1.64 \pm 0.01$ & $2.07 \pm 0.00$ & $0.91 \pm 0.10$ & $2.04 \pm 0.29$ \\
\hline$\mu^{\mathrm{c}}\left(\right.$ day $\left.^{-1}\right)$ & $0.07 \pm 0.02$ & $0.12 \pm 0.00$ & $0.10 \pm 0.00$ & $0.01 \pm 0.00$ & $0.04 \pm 0.03$ & $0.08 \pm 0.00$ & $0.00 \pm 0.00$ & $0.08 \pm 0.00$ & $0.00 \pm 0.00$ & $0.00 \pm 0.00$ & $0.05 \pm 0.01$ & $0.00 \pm 0.00$ & $0.09 \pm 0.01$ \\
\hline$\mu_{\max } \mathrm{d}\left(\mathrm{day}^{-1}\right)$ & $0.07 \pm 0.02$ & $0.12 \pm 0.00$ & $0.10 \pm 0.00$ & $0.29 \pm 0.01$ & $0.39 \pm 0.00$ & $0.09 \pm 0.00$ & $0.48 \pm 0.01$ & $0.04 \pm 0.02$ & $0.03 \pm 0.00$ & $0.60 \pm 0.00$ & $0.17 \pm 0.00$ & $0.07 \pm 0.01$ & $0.10 \pm 0.00$ \\
\hline$v^{\mathrm{e}}\left(\mathrm{g}_{\mathrm{DW}} / \mathrm{L}\right.$ day $)$ & $0.07 \pm 0.02$ & $0.12 \pm 0.016$ & $0.11 \pm 0.01$ & $0.04 \pm 0.00$ & $0.49 \pm 0.00$ & $0.08 \pm 0.01$ & $0.00 \pm 0.00$ & $0.06 \pm 0.00$ & $0.01 \pm 0.00$ & $0.03 \pm 0.00$ & $0.07 \pm 0.01$ & $0.00 \pm 0.00$ & $0.14 \pm 0.02$ \\
\hline$v_{\max }{ }^{f}\left(\mathrm{~g}_{\mathrm{DW}} / \mathrm{L}\right.$ day $)$ & $0.07 \pm 0.02$ & $0.12 \pm 0.016$ & $0.11 \pm 0.01$ & $0.47 \pm 0.08$ & $0.66 \pm 0.03$ & $0.15 \pm 0.01$ & $0.33 \pm 0.01$ & $0.42 \pm 0.00$ & $0.05 \pm 0.00$ & $0.82 \pm 0.00$ & $0.25 \pm 0.01$ & $0.11 \pm 0.00$ & $0.14 \pm 0.01$ \\
\hline
\end{tabular}

${ }^{\mathrm{a}}$ final biomass concentration, ${ }^{\mathrm{b}}$ maximum biomass concentration, ${ }^{\mathrm{c}}$ specific growth rate, ${ }^{\mathrm{d}}$ specific growth rate at $X_{\max },{ }^{\mathrm{e}}$ biomass productivity, ${ }^{\mathrm{f}}$ biomass productivity at $X_{\max }$. 
Table 3. Lipid production parameters of co-cultures used in the mixotrophic treatment of winery wastewaters from the first (W1) and second (W2) washing tanks and from the filtration apparatus (W3) at different concentrations in Bold's Basal Medium.

\begin{tabular}{|c|c|c|c|c|}
\hline Concentration & Wastewater & $\begin{array}{c}C_{\mathrm{L}}^{\mathrm{a}} \\
\left(\mathrm{g}_{\mathrm{L}} / 100 \mathrm{~g}_{\mathrm{DW}}\right)\end{array}$ & $\begin{array}{c}v_{\mathrm{L}}^{b} \\
\left(\mathrm{~g}_{\mathrm{L}} / 100 \mathrm{~L} \cdot \text { day }\right)\end{array}$ & $\begin{array}{c}v_{\text {Lmax }}{ }^{c} \\
\left(g_{L} / 100 \mathrm{~L} \cdot \text { day }\right)\end{array}$ \\
\hline \multirow{3}{*}{$10 \%$} & W1 & $8.36 \pm 1.70$ & $0.29 \pm 0.01$ & $0.29 \pm 0.01$ \\
\hline & W2 & $12.61 \pm 0.00$ & $1.13 \pm 0.01$ & $1.13 \pm 0.01$ \\
\hline & W3 & $12.31 \pm 0.00$ & $1.07 \pm 0.02$ & $1.07 \pm 0.02$ \\
\hline \multirow{3}{*}{$20 \%$} & W1 & $10.03 \pm 0.68$ & $0.29 \pm 0.00$ & $3.43 \pm 0.10$ \\
\hline & W2 & $13.34 \pm 3.00$ & $0.11 \pm 0.01$ & $7.10 \pm 0.22$ \\
\hline & W3 & $10.93 \pm 0.02$ & $1.14 \pm 0.01$ & $1.14 \pm 0.01$ \\
\hline \multirow{3}{*}{$50 \%$} & W1 & $9.98 \pm 0.04$ & $0.00 \pm 0.00$ & $2.31 \pm 0.09$ \\
\hline & W2 & $19.66 \pm 0.00$ & $0.00 \pm 0.00$ & $6.37 \pm 0.18$ \\
\hline & W3 & $21.95 \pm 0.00$ & $0.00 \pm 0.00$ & $2.41 \pm 0.12$ \\
\hline \multirow{4}{*}{$100 \%$} & W1 & $7.37 \pm 2.27$ & $0.00 \pm 0.00$ & $2.80 \pm 0.14$ \\
\hline & W2 & $7.30 \pm 0.00$ & $0.00 \pm 0.00$ & $1.43 \pm 0.13$ \\
\hline & W3 & $8.39 \pm 2.02$ & $0.00 \pm 0.00$ & $0.43 \pm 0.07$ \\
\hline & Control & $10.54 \pm 0.00$ & $1.08 \pm 0.09$ & $1.08 \pm 0.09$ \\
\hline
\end{tabular}

${ }^{\mathrm{a}}$ lipid content of biomass, ${ }^{\mathrm{b}}$ lipid productivity, ${ }^{\mathrm{c}}$ lipid productivity at $X_{\max }$.

The elementary composition of the co-culture biomass at the end of the growth was determined by a CHNS-O elemental analyzer (Table 4). Comparing nitrogen, sulfur and carbon contents of the positive control (C) with the biomass obtained after WWWs treatments, no significant difference could be observed. The hydrogen content was strongly increased from $2.93 \pm 0.43$ to $6.40 \pm 0.39$ using W3 at $10 \%(\mathrm{v} / \mathrm{v})$ and reduced to $0.09 \pm 0.13$ with $100 \%(\mathrm{v} / \mathrm{v})$ of W3.

Table 4. Co-culture elemental composition after the mixotrophic treatment of winery wastewaters from the first (W1) and second (W2) washing tanks and from the filtration apparatus (W3) at different concentrations in Bold's Basal Medium.

\begin{tabular}{|c|c|c|c|c|c|}
\hline Concentration & Wastewater & $\mathbf{H}$ & $\mathrm{C}$ & $\mathbf{N}$ & S \\
\hline & Control & $2.93 \pm 0.43^{b, c, d, e}$ & $38.43 \pm 1.08^{a, b}$ & $6.30 \pm 0.37^{\mathrm{a}, \mathrm{b}, \mathrm{c}}$ & $0.00 \pm 0.37^{a}$ \\
\hline \multirow{3}{*}{$10 \%(\mathrm{v} / \mathrm{v})$} & W1 & $4.78 \pm 0.43^{\mathrm{d}, \mathrm{e}, \mathrm{f}}$ & $40.60 \pm 1.08^{a, b}$ & $6.40 \pm 0.37^{\mathrm{a}, \mathrm{b}, \mathrm{c}}$ & $0.49 \pm 0.49^{a}$ \\
\hline & W2 & $5.48 \pm 0.56^{\mathrm{e}, \mathrm{f}}$ & $43.20 \pm 1.12^{a, b}$ & $6.84 \pm 0.17 \mathrm{~b}, \mathrm{c}$ & $0.00 \pm 0.00^{\mathrm{a}}$ \\
\hline & W3 & $6.40 \pm 0.39^{\mathrm{f}}$ & $42.50 \pm 3.64^{\mathrm{a}, \mathrm{b}}$ & $7.29 \pm 0.22^{a, b, c}$ & $0.08 \pm 0.09^{a}$ \\
\hline \multirow{3}{*}{$20 \%(\mathrm{v} / \mathrm{v})$} & W1 & $4.21 \pm 0.53^{\mathrm{d}, \mathrm{e}, \mathrm{f}}$ & $39.65 \pm 3.74^{a, b}$ & $6.20 \pm 0.3^{a, b, c}$ & $0.04 \pm 0.05^{a}$ \\
\hline & W2 & $4.14 \pm 0.25^{\mathrm{c}, \mathrm{d}, \mathrm{e}, \mathrm{f}}$ & $40.40 \pm 1.42^{a, b}$ & $6.60 \pm 0.33^{a, b, c}$ & $0.00 \pm 0.00^{\mathrm{a}}$ \\
\hline & W3 & $3.32 \pm 0.40^{\mathrm{b}, \mathrm{c}, \mathrm{d}, \mathrm{e}}$ & $41.95 \pm 1.02^{\mathrm{a}, \mathrm{b}}$ & $6.91 \pm 0.68^{b, c}$ & $0.00 \pm 0.00^{\mathrm{a}}$ \\
\hline \multirow{3}{*}{$50 \%(\mathrm{v} / \mathrm{v})$} & W1 & $1.14 \pm 0.07^{\mathrm{a}, \mathrm{b}}$ & $42.33 \pm 1.12^{a, b}$ & $6.49 \pm 0.14^{\mathrm{a}, \mathrm{b}, \mathrm{c}}$ & $0.00 \pm 0.00^{a}$ \\
\hline & W2 & $1.56 \pm 0.24^{a, b, c}$ & $42.74 \pm 1.12^{\mathrm{a}, \mathrm{b}}$ & $6.82 \pm 0.25 \mathrm{~b}, \mathrm{c}$ & $0.04 \pm 0.00^{\mathrm{a}}$ \\
\hline & W3 & $2.84 \pm 0.12^{b, c, d, e}$ & $36.58 \pm 1.02^{a}$ & $5.38 \pm 0.40^{\mathrm{a}}$ & $0.00 \pm 0.00^{\mathrm{a}}$ \\
\hline \multirow{3}{*}{$100 \%(v / v)$} & W1 & $1.04 \pm 0.60^{\mathrm{a}, \mathrm{b}}$ & $45.05 \pm 0.94^{b}$ & $5.79 \pm 0.28^{a, b}$ & $0.00 \pm 0.00^{\mathrm{a}}$ \\
\hline & W2 & $2.62 \pm 2.03^{a, b, c, d}$ & $39.67 \pm 1.63^{a, b}$ & $6.24 \pm 0.20^{a, b, c}$ & $0.00 \pm 0.00^{\mathrm{a}}$ \\
\hline & W3 & $0.09 \pm 0.13^{a}$ & $43.32 \pm 3.25^{a, b}$ & $6.58 \pm 0.68^{a, b, c}$ & $0.00 \pm 0.00^{\mathrm{a}}$ \\
\hline
\end{tabular}

Different letters (a-f) in the same column indicate statistically significant differences among mean values.

\subsection{COD Removal from Winery Wastewater}

Chemical oxygen demand (COD) has been accepted as a national standard for the evaluation of organic pollution in wastewater, besides being the most frequently used parameter to assess the efficiency of biological wastewater treatments. Since microalgae cultivated under mixotrophic condition have the ability to consume organic pollutants as a carbon source and inorganic nutrients for 
their growth, COD removal by the co-culture from the three different WWWs was daily determined to compare reduction trends.

The COD reduction curves followed the same trend in the different WWWs either as such or differently diluted. One can see in Figure 2 that the organic matter was quickly removed from the non-diluted WWWs by no less than $85 \%$ during the first 5 days of mixotrophic treatment, while after the exponential phase its removal proceeded slowly up to the end.

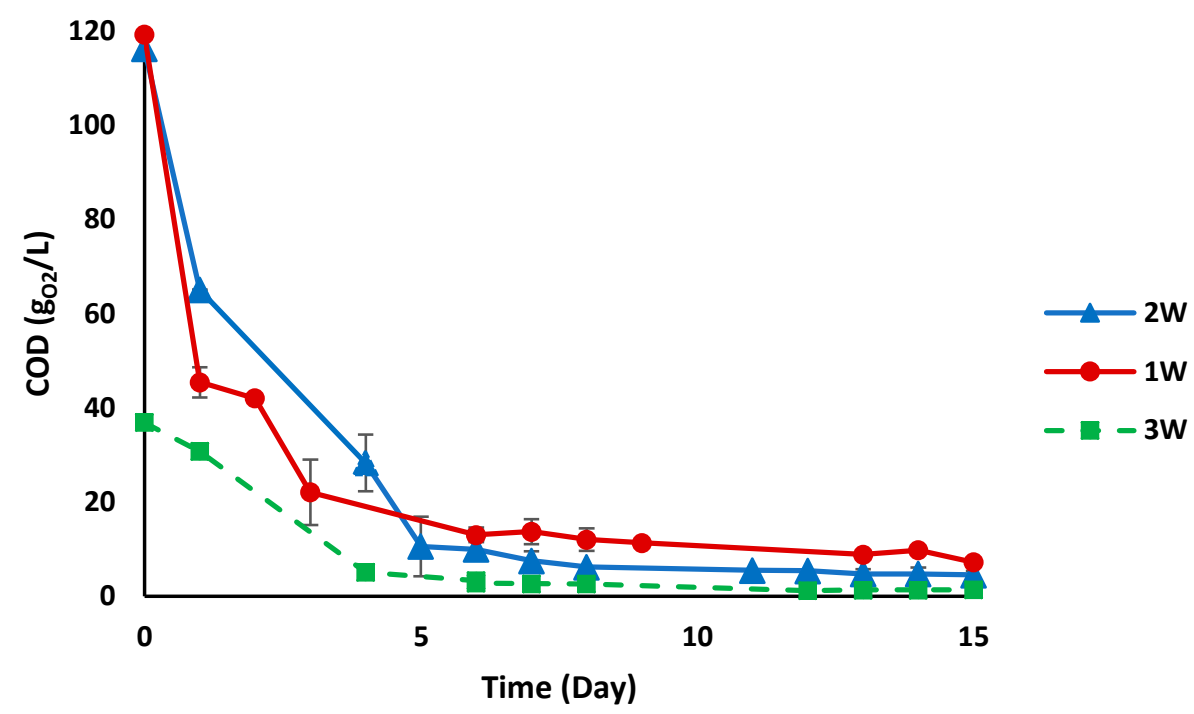

Figure 2. Time behavior of chemical oxygen demand in non-diluted winery wastewaters from the first (W1) and second (W2) washing tanks and from the filtration apparatus (W3) during treatment with the co-culture.

The residual COD assessed at the end of each treatment was used to calculate its percentage removal with respect to the initial COD, for which the results are depicted Figure 3A. One can see that at all the concentrations, the removal was higher than $90 \%$ in the three WWWs, with the highest value (around 99\%) being detected in 50\% (v/v) W2. In addition, Figure 3B, which illustrates the percent increases in COD removal at the end of every treatment compared with the respective negative controls (without inoculum), clearly shows that the co-culture, as expected, was much more effective than the autochthonous species (mainly yeast) present in the WWWs in reducing their COD contents.

Other microrganisms such as bacteria and fungi have been used to purify WWWs. Malandra et al. [26] reported the ability of a new yeast isolate (MEA5) to reduce by $95 \%$ the COD of a synthetic wastewater in a rotating biological contactor under aerated conditions, demonstrating the potential of a dynamic microbial population to treat WWW. Zhang et al. [27] observed a $90 \%$ reduction of WWW COD by microfungi such as Trichoderma viride, Aspergillus niger and Aspergillus oryzae.

Most of the attempts reported in the literature to reduce wastewater COD by microalgae have shown comparable or even better performance than conventional treatments. The most common winery wastewater treatment systems are conventional activated sludge plants or different anaerobic systems. However, despite their simplicity, they require long retention times to degrade the organic matter and can only be applied when cells have a small size and large surfaces are available. For instance, Torrijios and Moletta [28] reported a COD reduction in winery wastewater as high as $97.5 \%$ in a sequencing batch reactor.

\subsection{Polyphenols Removal}

It is well-known that microalgae have the ability to degrade polyphenols through two different mechanisms, namely mineralization to carbon dioxide [29] or biotransformation to other compounds, as suggested by Cerniglia et al. [30], who observed the biotransformation of naphthalene into other 
similar metabolites, such as 1-naphthol. So, in order to check the capability of the selected co-culture to reduce the polyphenol content $(\mathrm{PC})$ of WWWs, the total concentration of these substances was determined by the Folin-Ciocalteu assay before and after treatments.
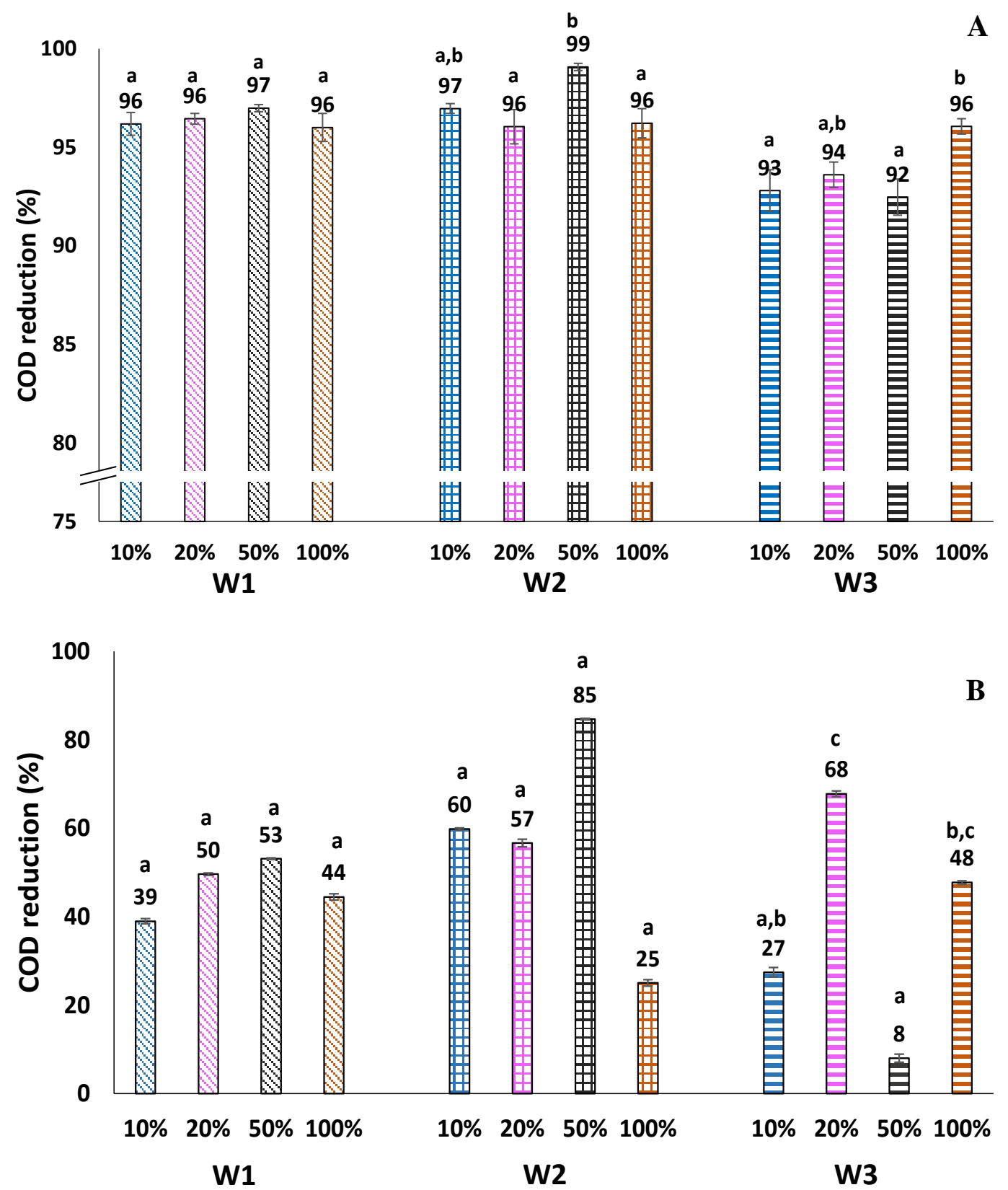

Figure 3. Chemical oxygen demand removals by the co-culture in winery wastewaters from the first (W1) and second (W2) washing tanks and from the filtration apparatus (W3) at different concentrations in Bold's Basal Medium. (A) Final COD removal compared to the start of each treatment. (B) Increase in final COD removal compared to the negative control of each treatment. Different letters $(\mathrm{a}-\mathrm{c})$ in the same group indicate statistically significant differences among mean values

Polyphenol degradation by the co-culture at the end of treatments was higher than $50 \%$ under all the tested conditions (Figure 4A). In general, the higher the WWW concentration and the PC content, the lower the polyphenol degradation. For instance, PC removal from W2 progressively decreased from $100 \%$ to $53 \%$ when its concentration in BBM was increased from 10 to $100(\mathrm{v} / \mathrm{v})$. Consistently, PC removal was the highest (100\%) in 10 and $20(\mathrm{v} / \mathrm{v}) \mathrm{W} 3$ and decreased to $77 \%$ and $60 \%$ 
in 50 and $100(\mathrm{v} / \mathrm{v})$, respectively. When comparing the three different WWWs, as expected W1 was the most recalcitrant to PC degradation, followed by W2 and W3, even though the PC were completely degraded in all three WWWs at the lowest concentration $(10 \mathrm{v} / \mathrm{v})$. In the same ways as COD, the percent increases in PC removal at the end of every treatment compared with the respective negative controls (without inoculum) were always quite high, ranging from $63 \%$ to $96 \%$ (Figure $4 \mathrm{~B}$ ). The most diluted WWWs $(10 \mathrm{v} / \mathrm{v})$ were the only exceptions, being all completely decontaminated from PC by either the microalgal co-culture or the autochthonous microflora.
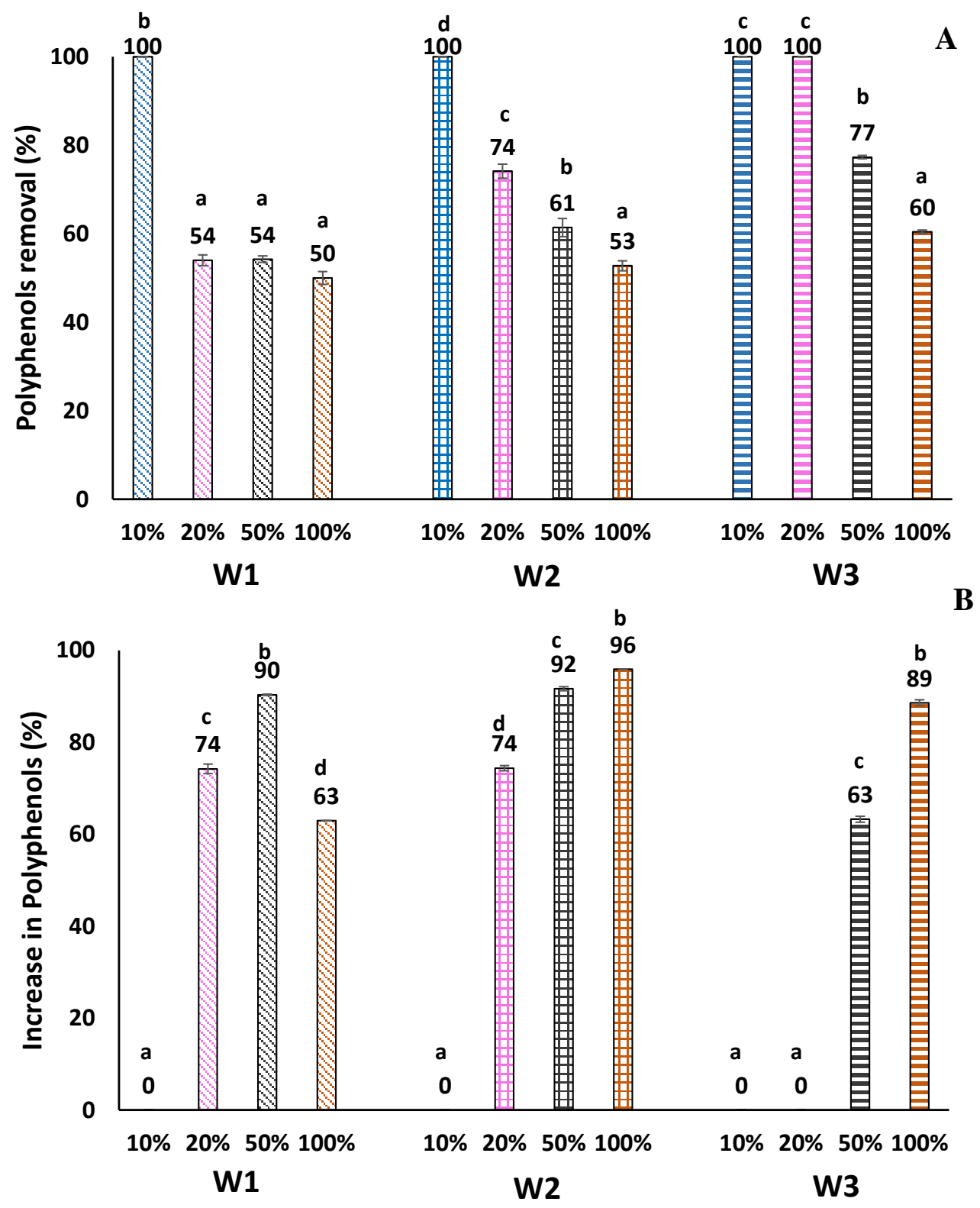

Figure 4. Removals of polyphenols (PC) by the co-culture in winery wastewaters from the first (W1) and second (W2) washing tanks and from the filtration apparatus (W3) at different concentrations in Bold's Basal Medium. (A) Final PC removal compared to the start of each treatment. (B) Increase in final PC removal compared to the negative control of each treatment. Different letters $(\mathrm{a}-\mathrm{c})$ in the same group indicate statistically significant differences among mean values

Similar results were obtained by other authors. To provide only a few examples, Pinto et al. [31], who investigated the removal of different phenolic compounds by Scenedesmus obliquus, 
reported removals of tyrosol and hydroxytyrosol higher than $50 \%$ and $68 \%$, respectively. Moreover, the same inverse correlation between polyphenol concentration and removal was observed by Papazi et al. [32] for olive mill wastewater treatment by the same microalga, in that tyrosol removal decreased from $75 \%$ to $15 \%$ when its concentration was increased from 0.05 to $0.3 \mathrm{mM}$.

Polyphenols and other high molecular weight pollutants of winery wastewater are not mineralized by WWW conventional biological treatments [13]. To achieve reductions in the content of polyphenolic compounds comparable to that obtained in the present study, expensive and complex technologies must be applied such as reverse osmosis, nanofiltration and ultrafiltration [33].

\section{Conclusions}

A Chlorella vulgaris and Arthrospira platensis co-culture was grown in three different winery wastewaters (WWWs), namely those from the first (W1) and second (W2) tank washings as well as that from the filtration equipment (W3).

The highest biomass concentration $\left(2.63 \pm 0.00 \mathrm{~g}_{\mathrm{DW}} / \mathrm{L}\right)$ was obtained in $20 \%(\mathrm{v} / \mathrm{v}) \mathrm{W} 2$ after only 4 days of treatment, corresponding to a biomass productivity of $0.66 \pm 0.03 \mathrm{~g}_{\mathrm{DW}} / \mathrm{L} \cdot$ day.

The co-culture was able to reduce the chemical oxygen demand and polyphenol content of the three WWWs by more than $92 \%$ and $50 \%$, respectively.

The lipid productivity increased considerably after the wastewater treatment.

The results suggest it is possible to stop the co-culture cultivation after the achievement of maximum biomass concentration in order to increase biomass and lipid productivities without losing the benefits in terms of reduction of the pollution load.

This study demonstrates the feasibility of using WWWs as a culture medium for the growth of microalgae in order to reduce their production costs and exploit the resulting biomass as a source of biofuels.

Author Contributions: Conceptualization, A.A.C. and E.S.; experimental methodology, A.A.C. and E.S; validation, A.A.C. and E.S.; writing-original draft preparation, A.A.C., E.S. and A.C.; writing - review and editing, A.A.C., E.S. and A.C.; visualization, A.A.C. E.S. and A.C.; supervision, A.A.C. and A.C.; project administration, A.C.; funding acquisition, A.C. All authors have read and agreed to the published version of the manuscript.

Funding: This research received no external funding.

Conflicts of Interest: The authors declare no conflict of interest.

\section{References}

1. Lisý, M.; Lisá, H.; Jecha, D.; Baláš, M.; Križan, P. Characteristic properties of alternative biomass fuels. Energies 2020, 13, 1448. [CrossRef]

2. Saad, M.G.; Dosoky, N.S.; Zoromba, M.S.; Shafik, H.M. Algal biofuels: Current status and key challenges. Energies 2019, 12, 1920. [CrossRef]

3. Song, M.; Pei, H. The growth and lipid accumulation of Scenedesmus quadricauda during batch mixotrophic/heterotrophic cultivation using xylose as a carbon source. Bioresour. Technol. 2018, 263, 525-531. [CrossRef] [PubMed]

4. Suganya, T.; Varman, M.; Masjuki, H.H.; Renganathan, S. Macroalgae and microalgae as a potential source for commercial applications along with biofuels production: A biorefinery approach. Renew. Sustain. Energy Rev. 2016, 55, 909-941. [CrossRef]

5. Da Silva Vaz, B.; Moreira, J.B.; de Morais, M.G.; Costa, J.A.V. Microalgae as a new source of bioactive compounds in food supplements. Curr. Opin. Food Sci. 2016, 7, 73-77. [CrossRef]

6. Sathasivam, R.; Radhakrishnan, R.; Hashem, A.; Abd_Allah, E.F. Microalgae metabolites: A rich source for food and medicine. Saudi J. Biol. Sci. 2019, 26, 709-722. [CrossRef]

7. Lam, M.K.; Lee, K.T. Microalgae biofuels: A critical review of issues, problems and the way forward. Biotechnol. Adv. 2012, 30, 673-690. [CrossRef]

8. Hu, J.; Nagarajan, D.; Zhang, Q.; Chang, J.S.; Lee, D.J. Heterotrophic cultivation of microalgae for pigment production: A review. Biotechnol. Adv. 2018, 36, 54-67. [CrossRef] 
9. Zhou, W.; Wang, Z.; Xu, J.; Ma, L. Cultivation of microalgae Chlorella zofingiensis on municipal wastewater and biogas slurry towards bioenergy. J. Biosci. Bioeng. 2018, 126, 644-648. [CrossRef]

10. Huy, M.; Kumar, G.; Kim, H.W.; Kim, S.H. Photoautotrophic cultivation of mixed microalgae consortia using various organic waste streams towards remediation and resource recovery. Bioresour. Technol. 2018, 247, 576-581. [CrossRef]

11. Ioannou, L.A.; Puma, G.L.; Fatta-Kassinos, D. Treatment of winery wastewater by physicochemical, biological and advanced processes: A review. J. Hazard. Mater. 2015, 286, 343-368. [CrossRef] [PubMed]

12. Gasol, C.M.; Rieradevall, J.; Ruggieri, L.; Cadena, E.; Martı, J.; Gabarrell, X.; Gea, T.; Sort, X.; Sa, A.; Valle, C. Recovery of organic wastes in the Spanish wine industry. Technical, economic and environmental analyses of the composting process. J. Clean. Prod. 2009, 17, 830-838. [CrossRef]

13. Singh, R.L.; Pratap, R. Advances in Biological Treatment of Industrial Waste Water and Their Recycling for a Sustainable Future; Springer: Berlin/Heidelberg, Germany, 2019; ISBN 978-981-13-1467-4.

14. Mohana, S.; Acharya, B.K.; Madamwar, D. Distillery spent wash: Treatment technologies and potential applications. J. Hazard. Mater. 2009, 163, 12-25. [CrossRef] [PubMed]

15. Federation, W.E. Standard Methods for the Examination of Water and Wastewater Part 1000 Standard Methods for the Examination of Water and Wastewater; American Public Health Association: Washington, DC, USA, 1999.

16. Ortiz Montoya, E.Y.; Casazza, A.A.; Aliakbarian, B.; Perego, P.; Converti, A.; De Carvalho, J.C.M. Production of Chlorella vulgaris as a source of essential fatty acids in a tubular photobioreactor continuously fed with air enriched with $\mathrm{CO}_{2}$ at different concentrations. Biotechnol. Prog. 2014, 30, 916-922. [CrossRef]

17. Casazza, A.A.; Ferrari, P.F.; Aliakbarian, B.; Converti, A.; Perego, P. Effect of UV radiation or titanium dioxide on polyphenol and lipid contents of Arthrospira (Spirulina) platensis. Algal Res. 2015, 12, 308-315. [CrossRef]

18. Brezoiu, A.; Matei, C.; Deaconu, M.; Stanciuc, A.; Trifan, A.; Gaspar-pintiliescu, A.; Berger, D. Polyphenols extract from grape pomace. Characterization and valorisation through encapsulation into mesoporous silica-type matrices. Food Chem. Toxicol. 2019, 133, 110787. [CrossRef]

19. Heredia-arroyo, T.; Wei, W.; Ruan, R.; Hu, B. Mixotrophic cultivation of Chlorella vulgaris and its potential application for the oil accumulation from non-sugar materials. Biomass Bioenergy 2011, 5. [CrossRef]

20. Andrade, M.R.; Costa, J.A.V. Mixotrophic cultivation of microalga Spirulina platensis using molasses as organic substrate. Aquaculture 2007, 264, 130-134. [CrossRef]

21. Ganeshkumar, V.; Subashchandrabose, S.R.; Dharmarajan, R.; Venkateswarlu, K.; Naidu, R.; Megharaj, M. Use of mixed wastewaters from piggery and winery for nutrient removal and lipid production by Chlorella $\mathrm{sp}$. MM3. Bioresour. Technol. 2018, 256, 254-258. [CrossRef]

22. Sati, H.; Mitra, M.; Mishra, S.; Baredar, P. Microalgal lipid extraction strategies for biodiesel production: A review. Algal Res. 2019, 38, 101413. [CrossRef]

23. Ferreira, G.F.; Ríos Pinto, L.F.; Maciel Filho, R.; Fregolente, L.V. A review on lipid production from microalgae: Association between cultivation using waste streams and fatty acid profiles. Renew. Sustain. Energy Rev. 2019, 109, 448-466. [CrossRef]

24. Santana, H.; Cereijo, C.R.; Teles, V.C.; Nascimento, R.C.; Fernandes, M.S.; Brunale, P.; Campanha, R.C.; Soares, I.P.; Silva, F.C.P.; Sabaini, P.S.; et al. Microalgae cultivation in sugarcane vinasse: Selection, growth and biochemical characterization. Bioresour. Technol. 2017, 228, 133-140. [CrossRef]

25. Kwak, H.S.; Kim, J.Y.H.; Woo, H.M.; Jin, E.S.; Min, B.K.; Sim, S.J. Synergistic effect of multiple stress conditions for improving microalgal lipid production. Algal Res. 2016, 19, 215-224. [CrossRef]

26. Malandra, L.; Wolfaardt, G.; Zietsman, A.; Viljoen-Bloom, M. Microbiology of a biological contactor for winery wastewater treatment. Water Res. 2003, 37, 4125-4134. [CrossRef]

27. Zhan, J.; Rong, J.; Wang, Q. Mixotrophic cultivation, a preferable microalgae cultivation mode for biomass/bioenergy production, and bioremediation, advances and prospect. Int. J. Hydrogen Energy 2016, 42, 8505-8517. [CrossRef]

28. Torrijos, M.; Moletta, R. Winery wastewater depollution by sequencing batch reactor. Water Sci. Technol. 1997, 35, 249-257. [CrossRef]

29. Lindner, A.V.; Pleissner, D. Utilization of phenolic compounds by microalgae. Algal Res. 2019, 42, 101602. [CrossRef]

30. Cerniglia, C.E.; Gibson, D.T.; Van Baalen, C. Oxidation of naphthalene by cyanobacteria and microalgae. J. Gen. Microbiol. 1980, 116, 495-500. [CrossRef] 
31. Pinto, G.; Pollio, A.; Previtera, L.; Temussi, F. Biodegradation of phenols by microalgae. Biotechnol. Lett. 2002, 24, 2047-2051. [CrossRef]

32. Papazi, A.; Ioannou, A.; Symeonidi, M.; Doulis, A.G.; Kotzabasis, K. Bioenergetic strategy of microalgae for the biodegradation of tyrosol and hydroxytyrosol. Z. Fur Nat. Sect. C J. Biosci. 2017, 72, 227-236. [CrossRef]

33. Ferrarini, R.; Versari, A.; Galassi, S. A preliminary comparison between nanofiltration and reverse osmosis membranes for grape juice treatment. J. Food Process. Eng. 2001, 50, 113-116. [CrossRef]

(C) 2020 by the authors. Licensee MDPI, Basel, Switzerland. This article is an open access article distributed under the terms and conditions of the Creative Commons Attribution (CC BY) license (http://creativecommons.org/licenses/by/4.0/). 